05,13

\title{
Магнитооптические свойства висмутзамещенных пленок ферритов-гранатов в сильных импульсных магнитных полях
}

\author{
(C) Ю.Б. Кудасов ${ }^{1,2}$, М.В. Логунов ${ }^{3}$, Р.В. Козабаранов ${ }^{1}$, И.В. Макаров ${ }^{2}$, В.В. Платонов ${ }^{1,2}$, \\ О.М. Сурдин ${ }^{1,2}$, Д.А. Маслов ${ }^{1,2}$, А.С. Коршунов ${ }^{2}$, Е.Я. Попов ${ }^{1}$, А.С. Светлов ${ }^{1}$ \\ ${ }^{1}$ Саровский фризико-технический институт, \\ Национальный исследовательский ядерный университет „МИФИ“, \\ Саров, Россия \\ ${ }^{2}$ Российский фредеральный ядерный центр - \\ Всероссийский научно-исследовательский институт экспериментальной физики, \\ Саров, Россия \\ ${ }^{3}$ Институт радиотехники и электроники РАН, \\ Москва, Россия \\ E-mail: kudasov@ntc.vniief.ru
}

\begin{abstract}
Представлена методика измерения поворота плоскости поляризации света в импульсных магнитных полях напряженностью до $40 \mathrm{~T}$ с чувствительностью около $0.1 \mathrm{deg}$. Исследован эффект Фарадея в пленках разбавленных ферритов-гранатов $(\mathrm{Lu}, \mathrm{Bi})_{3}(\mathrm{Fe}, \mathrm{Ga}, \mathrm{Al})_{5} \mathrm{O}_{12}$ в диапазоне температур от комнатной до $78 \mathrm{~K}$, включая окрестность температуры компенсации магнитного момента. Показано, что переход к неколлинеарной фазе на магнитной фазовой диаграмме происходит при напряженности магнитного поля более 30 Т при комнатной температуре, пороговое поле перехода стремится к нулю при приближении к температуре компенсации магнитного момента.
\end{abstract}

Работа выполнена при поддержке РФФИ (проекты № 16-08-00337 и № 18-52-16006 НЦНИЛ_а), РНФ (проект № 14-19-00760) и программы повышения конкурентоспособности НИЯУ МИФИ.

DOI: 10.21883/FTT.2018.11.46658.13NN

\section{1. Введение}

Ферриты-гранаты являются ферримагнетиками, прозрачными в видимом и ближнем инфракрасном диапазонах. Благодаря своим уникальным свойствам они широко применяются в магнитооптических устройствах [1-3] и представляют интерес для сверхбыстродействующих устройств записи и обработки информации [4,5]. Особенностью ферритов-гранатов является многоподрешеточная магнитная структура, значительные возможности варьрования состава и, как следствие, разнообразие их магнитных и оптических свойств.

Ферриты-гранаты позволяют создавать твердые растворы замещения, в которых ионы металлов располагаются в трех кристаллографических позициях. Редкоземельные ионы находятся в додекаэдрическом окружении, а ионы железа $\mathrm{Fe}^{3+}$ (в состоянии с полным спином $S=5 / 2)$ - в двух позициях: октаэдрической (индекс $a)$ и тетраэдрической (индекс $d$ ). Соотношение ионов железа в подрешетках составляет $\mathrm{Na}: \mathrm{Nd}=2: 3$. Таким образом, в случае немагнитного иона в додекаэдрической позиции, например, $\mathrm{Y}^{3+}$ или $\mathrm{Lu}^{3+}$, феррит-гранат является двухподрешеточным ферримагнетиком. Замещение железа немагнитными ионами $\left(\mathrm{Ga}^{3+}, \mathrm{Al}^{3+}\right)$ позволяет избирательно разбавлять магнитные подрешетки. Так, ионы галлия занимают в основном тетраэдрические позиции $[6,7]$. В зависимости от технологических факторов (температура отжига, состав и т. д.) до 90-95\% замещенных галлием узлов могут оказаться в тетраэдрической позиции [8]. Это позволяет синтезировать ферримагнети- ки как с точкой компенсации магнитных моментов $[1,6]$, так и с точкой компенсации момента импульса $[9,10]$, что представляют интерес для создания быстродействующих устройств спинтроники. Следует также отметить, что разбавление редкоземельной подрешетки висмутом приводит к заметным изменениям магнитных свойств и значительному росту эффекта Фарадея, что привлекает большое внимание к частично и полностью висмутзамещенным ферритам-гранатам $[1-3,7]$.

Подавляющее большинство магнитооптических исследований монокристаллов и пленок ферритов-гранатов посвящено их спектральным характеристикам (эффекта Фарадея и магнитного кругового дихроизма) в слабых магнитных полях $[7,11]$. При интерпретации экспериментальных данных при этом возникает неопределенность, связанная с разделением вкладов октаэдрической и тетраэдрической подрешеток, тем более, что в некоторых моделях предполагается значительная роль коллективных эффектов, связанных с ионами обеих подрешеток. Магнитооптические измерения в сильных магнитных полях $[12,13]$ позволяют изменить антиферромагнитную взаимную ориентацию подрешеток железа вплоть до ферромагнитного упорядочения, что открывает возможности разделения вкладов подрешеток в эффект Фарадея и магнитный круговой дихроизм.

Настоящая работа посвящена изучению эффекта Фарадея в пленках разбавленных ферритов-гранатов в магнитных полях, напряженности которых достаточны для перехода к неколлинеарной фазе на магнитной фазовой диаграмме феррита-граната. 


\section{2. Методика эксперимента}

Для проведения измерений в сильных импульсных магнитных полях была использована установка, описанная в работе [14]. Соленоид для создания сильного магнитного поля с рабочим отверстием $19 \mathrm{~mm}$ находился в ванне с жидким азотом. Импульс магнитного поля имел амплитуду до $40 \mathrm{~T}$ и длительность около $10 \mathrm{~ms}$. В рабочем отверстии соленоида располагался оптический криостат. Для расширения температурного диапазона в криостате вблизи образца был дополнительно установлен миниатюрный нагреватель. Температура исследуемого образца могла варьироваться от $77 \mathrm{~K}$ до комнатной температуры. В качестве образца использована пленка состава $\left(\mathrm{Lu}_{3-x} \mathrm{Bi}_{x}\right)\left(\mathrm{Fe}_{5-y-z} \mathrm{Ga}_{y} \mathrm{Al}_{z}\right) \mathrm{O}_{12}(x \sim 0.8, y \sim 1$, $z \sim 0.8$ ), выращенная методом жидкофазной эпитаксии на подложке гадолиний галлиевого граната $\mathrm{Gd}_{3} \mathrm{Ga}_{5} \mathrm{O}_{12} \mathrm{c}$ ориентацией (111). Толщина пленки составляла $8.3 \mu \mathrm{m}$, подложки $-0.5 \mathrm{~mm}$ [15]. Пленка имела температуру компенсации от $10 \mathrm{~K}$ до $110 \mathrm{~K}$ согласно предварительным магнитооптическим измерениям доменной структуры.

Схема измерения угла поворота плоскости поляризации в магнитном поле представлена на рис. 1. В качестве источника излучения использовался гелий-неоновый лазер с длиной волны $633 \mathrm{~nm}$. Зондирующее излучение с такой длиной волны обеспечивает относительно большие углы поворота плоскости поляризации в ферритегранате при незначительном магнитном круговом дихроизме [11]. Кроме того, в этом диапазоне длин волн константа Верде подложки не зависит от температуры [16], что упрощает анализ результатов измерений эффекта Фарадея в пленке феррита-граната. Для повышения чувствительности установки до $\sim 0.1 \mathrm{deg}$ применена дифференциальная схема регистрации сигнала. Плоскополяризованное излучение лазера после прохождения через исследуемый образец разделяется на два ортогонально поляризованных пучка, угол поворота плоскости поляризации определяется по нормированной разности интенсивностей излучения в этих пучках (рис. 1).

При прохождении эллиптически поляризованного излучения через поляризационную призму две комплексные компоненты $E_{x}$ и $E_{y}$ могут быть описаны в формализме матриц Джонса [1]

$$
\left(\begin{array}{c}
E_{x} \\
E_{y}
\end{array}\right)=E_{0}\left(\begin{array}{cc}
\cos (\theta) & -\sin (\theta) \\
\sin (\theta) & \cos (\theta)
\end{array}\right)\left(\begin{array}{c}
\cos (\psi) \\
i \sin (\psi)
\end{array}\right),
$$

где $E_{0}-$ начальная комплексная амплитуда, $\theta=\theta_{0}+\delta \theta-$ угол наклона, $\theta_{0}-$ начальный угол, $\delta \theta-$ вращение в магнитном поле, $\psi-$ угол эллиптичности излучения.

Сигналы с фотоприемников пропорциональны мощности падающего излучения $\left(I_{1}=\left|E_{x}\right|^{2}\right.$ и $\left.I_{2}=\left|E_{y}\right|^{2}\right)$. После преобразований получаем:

$$
\Delta=\frac{I_{1}-I_{2}}{I_{1}+I_{2}}=\cos (2 \theta) \cos (2 \psi) .
$$

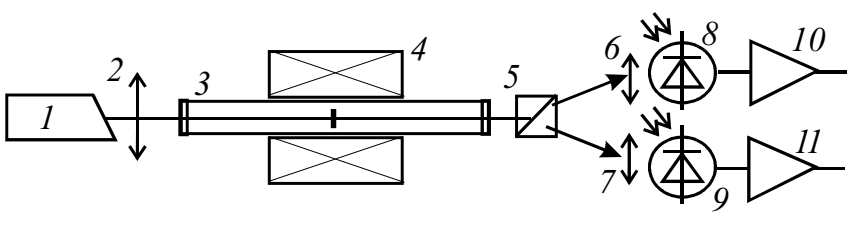

Рис. 1. Блок-схема установки для измерения угла поворота плоскости поляризации в сильных магнитных полях: 1 - лазер, 2 - поляризатор, 3 - криостат с образцом, 4 - соленоид, 5 - призма Волластона, 6,7 - анализаторы, 8,9фотодиоды, 10, 11 - предусилители.

При начальном угле $\theta_{0}=\pi / 4$ это отношение становится равным

$$
\Delta=\sin (2 \delta \theta) \cos (2 \psi) .
$$

Следует отметить, что при малой толщине пленки (малые углы $\delta \theta$ и $\psi$ ) это выражение совпадает с полученным из закона Малюса [17] $\Delta \approx \sin (2 \delta \theta)$. В выражение (3) не входит интенсивность исходного излучения $\left(I_{0}=\left|E_{0}\right|^{2}\right)$, благодаря чему устраняется влияние дрейфа мощности излучения лазера на результаты измерений.

\section{3. Результаты измерений}

На первом этапе были проведены измерения константы Верде подложки (без магнитной пленки) в магнитных полях до 20T при комнатной температуре. Поворот плоскости поляризации излучения в подложке был линеен по величине магнитного поля, и константа Верде составила $V_{S}=0.353 \mathrm{deg} / \mathrm{T}$ (для толщины подложки $0.5 \mathrm{~mm}$ ), что хорошо согласуется с результатами предшествующих работ $[16,18](\approx 0.358 \mathrm{deg} / \mathrm{T})$.

При измерении вращения плоскости поляризации в образце (пленке на подложке) полученные значения углов поворота $\theta$ корректировались учетом вращения плоскости поляризации в подложке, т.е. $\theta \rightarrow \theta-\mu_{0} H V_{S}$, где $\mu_{0}-$ магнитная проницаемость вакуума, $H-$ напряженность магнитного поля в соленоиде. На рис. 2 показаны результаты нескольких измерений вращения плоскости поляризации в пленке $(\mathrm{Lu}, \mathrm{Bi})_{3}(\mathrm{Fe}, \mathrm{Ga}, \mathrm{Al})_{5} \mathrm{O}_{12}$ при различных температурах. Во всех экспериментах, кроме проведенного при комнатной температуре, наблюдались особенности, связанные с изменением магнитной структуры в сильном магнитном поле. В слабом поле наблюдался переход от коллинеарной ферримагнитной структуры к угловой фазе при напряженности магнитного поля $H_{C 1}$ с сильным нелинейным изменением угла поворота. В сильных магнитных полях (> 15-20 T) происходил переход к слабой линейной зависимости при напряженности магнитного поля $H_{C 2}$. Следует отметить, что определить положение перехода $H_{C 2}$ непросто из-за очень плавного изменения режима вращения плоскости поляризации излучения. При низких температурах наблюдалась небольшая ступенька при переходе к неколлинеарной структуре при напряженности магнитного поля $H_{C 1}$. 

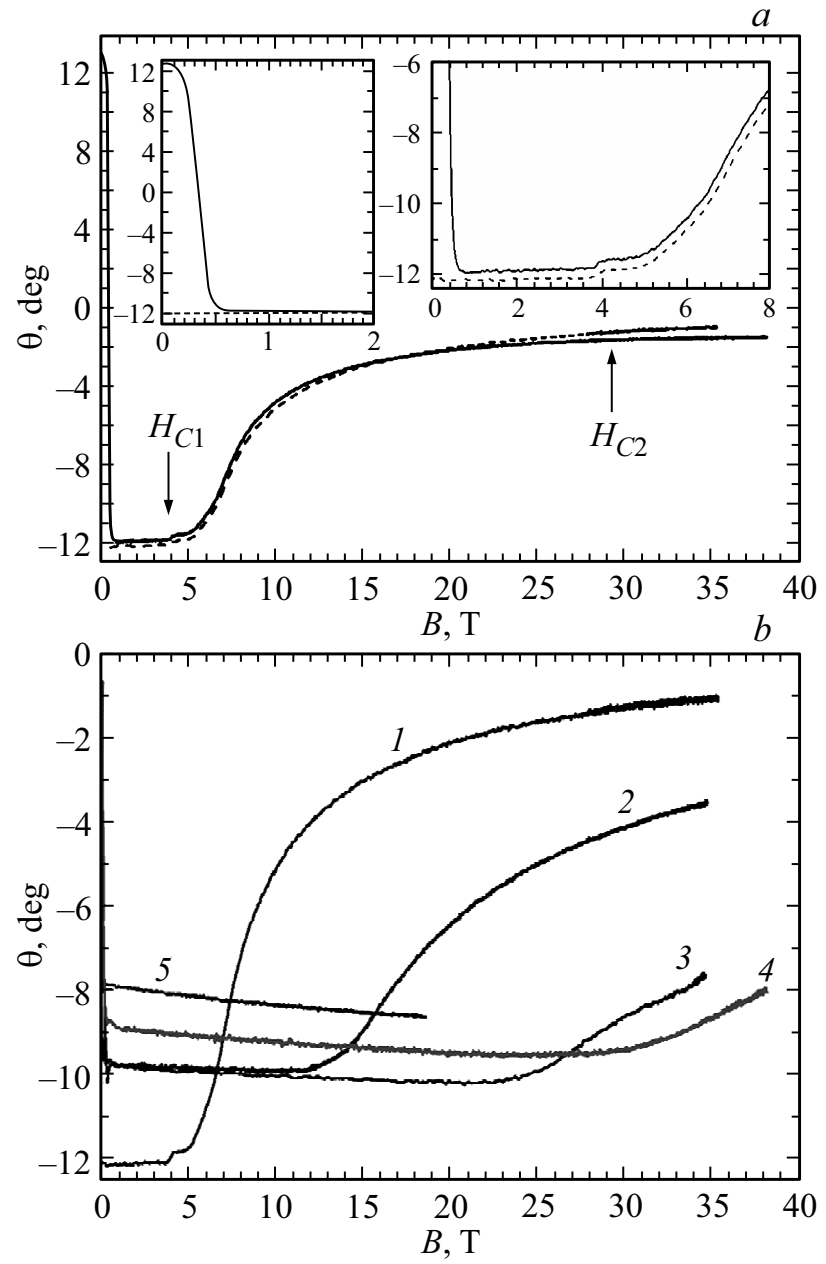

Рис. 2. Зависимости угла поворота плоскости поляризации $\theta$ в пленке $(\mathrm{Lu}, \mathrm{Bi})_{3}(\mathrm{Fe}, \mathrm{Ga}, \mathrm{Al})_{5} \mathrm{O}_{12}$ от напряженности магнитного поля $B$. (a) $\theta(B)$ при $T=78 \mathrm{~K}$, с предварительным намагничиванием вдоль приложенного поля (пунктирная линия) и в противоположном направлении (сплошная линия); на вставках показаны увеличенные фрагменты зависимостей. (b) $\theta(B)$ при температурах $78 \pm 1 \mathrm{~K}(1), 149 \pm 2 \mathrm{~K}(2), 209 \pm 3 \mathrm{~K}$ (3), $231 \pm 3 \mathrm{~K}(4), 293 \pm 1 \mathrm{~K}(5)$.

Одной из особенностей проводимых измерений был однополярный характер магнитного поля [14]. При низких температурах (вблизи точки компенсации) магнитное состояние образца сохранялось при выключении магнитного поля из-за повышения коэрцитивной силы пленки при приближении к температуре компенсации. На рис. 2, a показаны результаты двух экспериментов при температуре $78 \mathrm{~K}$, в первом из которых пленка была предварительно намагничена вдоль магнитного поля, генерируемого установкой, а во втором - в противоположном направлении. Видно, что в эксперименте со встречным предварительным намагничиванием в магнитном поле около $0.3 \mathrm{~T}$ произошел разворот плоскости поляризации. Из этого можно сделать вывод, что поле насыщения пленки превышает $\sim 0.3 \mathrm{~T}$ (что может быть связано с увеличением коэрцитивной силы пленки по мере приближения к температуре компенсации магнитного момента), а точка температурной компенсации магнитных моментов подрешеток лежит ниже $78 \mathrm{~K}$.

\section{4. Обсуждение результатов}

$\mathrm{B}$ рамках простейшей модели вращение плоскости поляризации в пленках $\left(\mathrm{Lu}_{1-x} \mathrm{Bi}_{x}\right)_{3}\left(\mathrm{Fe}_{1-y-z} \mathrm{Ga}_{y} \mathrm{Al}_{z}\right)_{5} \mathrm{O}_{12}$ описывается двумя диамагнитными переходами, соответствующими октаэдрической и тетраэдрической подрешеткам железа $[1,7,11]$. Согласно $[1,19]$ угол поворота плоскости поляризации в феррите-гранате с немагнитными ионами в додекаэдрической подрешетке может быть представлен следующим выражением:

$$
\theta=A M_{a}+D M_{d}
$$

где $A$ и $D$ - коэффициенты, зависящие от степени замещения редкоземельного иона висмутом, $M_{a}$ и $M_{d}-$ проекции магнитных моментов октаэдрической и тетраэдрической подрешеток вдоль направления распространения света. Отметим, что коэффициенты $A$ и $D$ заметно отличаются друг от друга, т.е. ионы железа, находящихся в двух подрешетках, дают различные вклады в фарадеевское вращение. Магнитные моменты октаэдрической и тетраэдрической подрешеток развернуты в противоположных направлениях из-за антиферромагнитного взаимодействия между ними, и поэтому вклады от этих подрешеток в фарадеевское вращение и магнитный круговой дихроизм на длине волны $633 \mathrm{~nm}$ имеют различные знаки. Полученные значения начального угла поворота хорошо согласуются с параметрами модели из работ $[7,11]$.

На зависимостях $\theta(B)$ (рис. 2) отчетливо виден переход к неколлинеарной фазе на магнитной фазовой диаграмме при напряженности магнитного поля $H_{C 1}$. В антиферромагнетике спин-флоп переход является переходом первого рода [2], а в ферримагнетике вблизи точки компенсации происходит быстрый, но непрерывный разворот подрешеток поперек направления магнитного поля, что и наблюдается выше критического поля $H_{C 1}$ до характерного магнитного поля $H_{C 2}$. Выше $H_{C 2}$ происходит схлопывание подрешеток к направлению магнитного поля. Здесь следует заметить, что обменное взаимодействием между подрешетками железа в феррите-гранате очень сильное и, как правило, соответствует магнитным полям более 100 Т [20,21]. Оценки из теории среднего поля с параметрами, соответствующему пленке $\left(\mathrm{Lu}_{2.2} \mathrm{Bi}_{0.8}\right)\left(\mathrm{Fe}_{3.2} \mathrm{Ga}_{1} \mathrm{Al}_{0.8}\right) \mathrm{O}_{12}$ [6,21], дают оценку поля спин-флип перехода порядка 570 T. Это значение более чем на порядок превышает максимальное значение в наших экспериментах. Поэтому в магнитных полях выше $H_{C 2}$ мы наблюдаем очень слабое изменение угла поворота плоскости поляризации. Похожее поведение наблюдалось в разбавленном гольдмиевом ферритегранате [13,22]. 


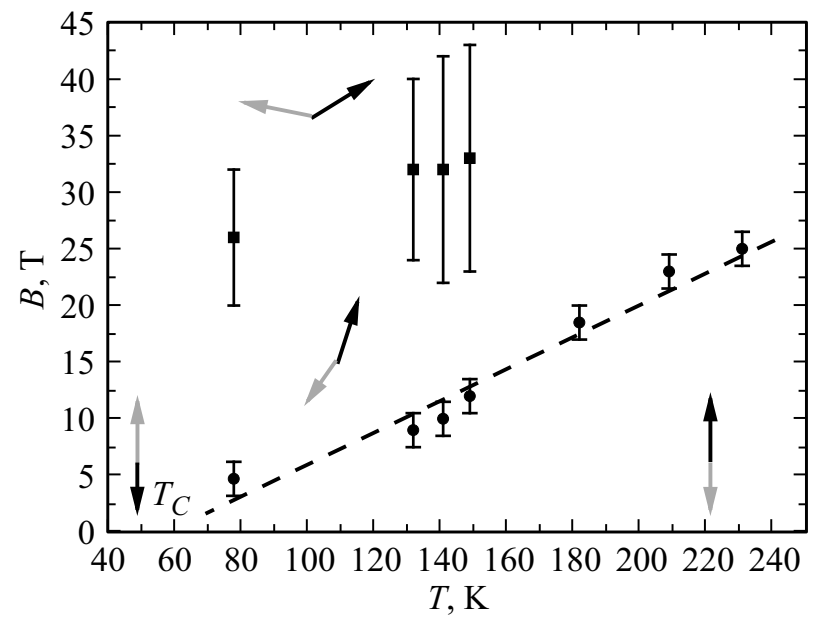

Рис. 3. Магнитная фазовая диаграмма пленки ферритаграната. Изменение магнитных фаз показано схематично. Круглые маркеры соответствуют пороговому полю перехода в неколлинеарную фазу $H_{C 1}$, квадратные маркеры - полю $H_{C 2}$.

На рис. 3 приведена фазовая диаграмма ферритаграната, построенная на основании результатов проведенных экспериментов. Переход к неколлинеарной фазе на магнитной фазовой диаграмме происходит при напряженности магнитного поля от 4 до 25 Т в зависимости от температуры феррита-граната, поле перехода снижается по мере приближения к температуре компенсации магнитного момента. Большая погрешность в определении $H_{C 2}$ связана с плавным характером вращения плоскости поляризации. Температуру компенсации по полученным результатам измерений можно оценить как $65 \pm 10 \mathrm{~K}$ (см. пунктирную линию на рис. 3).

\section{5. Заключение}

В работе представлена методика измерения малых углов поворота плоскости поляризации света в импульсных магнитных полях. Чувствительность методики составляет около $0.1 \mathrm{deg}$. Выполнены измерения эффекта Фарадея в пленке $(\mathrm{Lu}, \mathrm{Bi})_{3}(\mathrm{Fe}, \mathrm{Ga}, \mathrm{Al})_{5} \mathrm{O}_{12}$ при температуpax от комнатной до $78 \mathrm{~K}$ в магнитных полях до $40 \mathrm{~T}$. Показано, что переход к неколлинеарной фазе на магнитной фазовой диаграмме феррита-граната происходит при напряженности магнитного поля $H_{C 1}>30 \mathrm{~T}$ при комнатной температуре, поле $H_{C 1}$ стремится к нулю при приближении к температуре компенсации магнитного момента.

\section{Список литературы}

[1] A.K. Zvezdin, V.A. Kotov. Modern magnetooptics and magnetooptical materials. Institute of Physics Publishing, Bristol and Philadelphia (1997). $381 \mathrm{p}$.

[2] В.А. Боков. Физика магнетиков. Невский Диалект, СПб. (2002). $271 \mathrm{c}$.
[3] L. Bi, J. Hu, P. Jiang, H.S. Kim, D.H. Kim, M.C. Onbasli, G.F. Dionne, C.A. Ross. Materials 6, 5094 (2013).

[4] M. Deb, M. Vomir, J.-L. Rehspringer, J.-Y. Bigot. Appl. Phys. Lett. 107, 252404 (2015).

[5] A. Stupakiewicz, K. Szerenos, D. Afanasiev, A. Kirilyuk, A.V. Kimel. Nature 542, 71 (2017).

[6] P. Hansen, P. Röschmann, W. Tolksdorf. J. Appl. Phys. 45, 2728 (1974).

[7] L.E. Helseth, R.W. Hansen, E.I. Il'yashenko, M. Baziljevich, T.H. Johansen. Phys. Rev. B 64, 174406 (2001).

[8] P. Röschmann, P. Hansen. J. Appl. Phys. 52, 6257 (1981).

[9] Н.А. Логинов, М.В. Логунов, В.В. Рандошкин. ФТТ 31, 10, 58 (1989).

[10] В.В. Волков, В.А. Боков. ФТТ 50, 193 (2008).

[11] M. Deb, E. Popova, A. Fouchet, N. Keller. J. Phys. D 45, 455001 (2012).

[12] Р.В. Писарев, И.Г. Синий, Г.А. Смоленский. Письма в ЖЭТФ 9, 294 (1969).

[13] В.В. Дружинин, А.И. Павловский, О.М. Таценко, А.С. Лагутин, В.В. Платонов. ФТТ 34, 3755 (1992).

[14] Ю.Б. Кудасов, И.В. Макаров, Д.А. Маслов, В.В. Платонов, Е.Я. Попов, О.М. Сурдин, С.Л. Воронов, А.Ю. Малышев, С.В. Коротков, Ю.В. Аристов, В.М. Водовозов. ПТЭ 6, 78 (2015).

[15] M.V. Gerasimov, M.V. Logunov, A.V. Spirin, Y.N. Nozdrin, I.D. Tokman. Phys. Rev. B 94, 014434 (2016).

[16] А.К. Звездин, С.В. Копцик, Г.С. Кринчик, Р.З. Левитин, В.А. Лысков, А.И. Попов. Письма в ЖЭТФ 37, 331 (1983).

[17] В.В. Алексеев, Ю.Б. Кудасов, В.В. Шкарубский. ПТЭ 4, 151 (1988).

[18] P. Novotný, M. Křižánková, P. Boháček. J. Anal. Sci. Meth. Instr. 3, 13 (2013).

[19] P. Hansen, C.-P. Klages, J. Schuldt, K. Witter. Phys. Rev. B 31, 5858 (1985).

[20] N. Miura, I. Oguro, S. Chikazumi. J. Phys. Soc. Jpn 45, 1534 (1978).

[21] A.K. Zvezdin. In: Handbook of Magnetic Materials. / Ed. K.H.J. Buschow, Elsevier Science (1995) V. 9.405 p.

[22] V.V. Druzhinin, A.I. Pavlovskii, V.V. Platonov, O.M. Tatsenko, A.S. Lagutin. Physica B 177, 315, (1992).

Редактор К.В. Емцев 